\title{
Post Peak Behavior of Carbonated Concrete Structure - A Case Study of the Former Shime Mining Office Vertical Derrick in Japan
}

\author{
Kaiting Su ${ }^{1}$, Kei-ichi Imamoto ${ }^{2}$, Takafumi Noguchi ${ }^{3}$, Manabu Kanematsu ${ }^{4}$, Hitoshi \\ Hamasaki $^{5}$, Kohji Teranishi ${ }^{6}$, Chizuru Kiyohara ${ }^{7}$ and Munenori Yamada ${ }^{8}$ \\ 1 Tokyo University of Science, viki417@gmail.com \\ 2 Tokyo University of Science, imamoto@rs.kagu.tus.ac.jp \\ 3 The University of Tokyo, noguchi@bme.arch.t.u-tokyo.ac.jp \\ 4 Tokyo University of Science, manabu@rs.noda.tus.ac.jp \\ 5 Shibaura Institute of Technology, hamasaki@shibaura-it-ac.jp \\ 6Meijo University, ktera@meijo-u.ac.jp \\ 7 Tokyo University of Science, ckiyo@rs.tus.ac.jp \\ ${ }^{8}$ Center for Better Living, m-yamada@tbtl.org
}

\begin{abstract}
This paper is a report on the investigation results of the Former Shime Mining Office Vertical Derrick, which was built in 1943 and was 75 years old at the time of the investigation. The building suffered from serious deterioration including rebar corrosion, which led to large area of concrete spalling. In this report, aggregation data of concrete spalling has been presented along with the investigation results of cover thickness. According to the investigation results, concrete spalling occurred in places where cover thickness was less than $25 \mathrm{~mm}$. And According to the aggregation data, concrete spalling flakes increased by approximately 200 pieces per year, with the average size of $10 \mathrm{~cm}$ in diameter. Also, a possible relation between concrete spalling and rainfall was observed during the investigation. Equations using the proportion of wet area affected by rainfall to estimate the area of spalling are proposed, although the value of empirical coefficientoneeds further discussion, including collecting data from other buildings where spalling occurs.
\end{abstract}

Keywords: Durability, Historical Buildings, Concrete Spalling, Concrete Moisture, Rebar Corrosion.

\section{Introduction}

Concrete moisture is known to be a key parameter of rebar corrosion which leads to spalling and deterioration of the concrete structure. While reports on evolution of water content in real structures are still scarce, This paper is a report on the investigation results of the Former Shime Mining Office Vertical Derrick, which was 75 years old at the time of the investigation and had suffered from severe deterioration including rebar corrosion, which led to large area of concrete spalling. In addition, a possible relation between concrete spalling and rainfall was observed.

The introduction and the photo of the Former Shime Mining Office Vertical Derrick are shown in Table 1 and Figure 1. 


\section{Approach}

To monitor the inner relative humidity evolution where the concrete cover was thin, from June $1^{\text {st }}$ to July $25^{\text {th }}, 2018$, several thermo-hygrometers were implanted inside the concrete with cover thickness of $10 \mathrm{~mm}$ and $40 \mathrm{~mm}$. Concrete spalling had been observed and calculated every 3 months since February 2011. Cover thickness was measured with an electromagnetic radar method or a scale according to the condition of the cover.

Table 1. Introduction of the Former Shime Mining Office Vertical Derrick.

\begin{tabular}{|c|c|c|c|}
\hline Location & Shime town, Fukuoka & Structure & RC \\
\hline Owner & Shime town & Completion & May, 1943 \\
\hline \multirow{2}{*}{ Size } & height & 47.6 \\
\cline { 2 - 3 }$(m)$ & length & 15.3 \\
\cline { 2 - 3 } & width & 12.3 \\
\hline
\end{tabular}
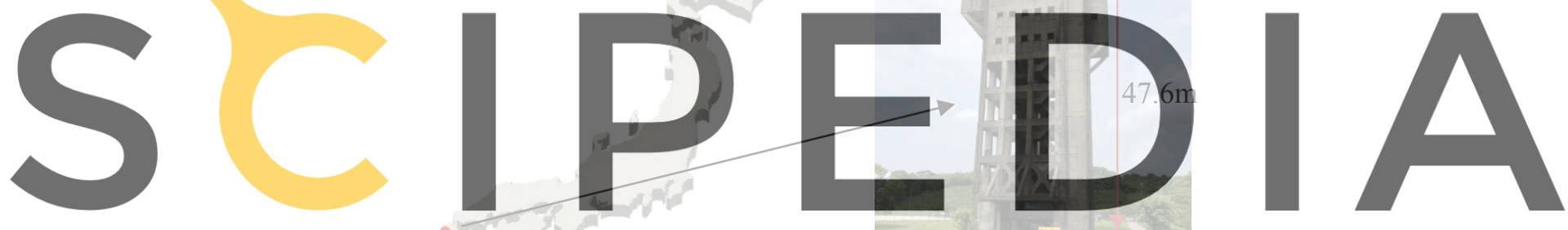

Register for free at https//www.scipedia.com to download the version without the watermark

Figure 1. Photo of the Former Shime Mining Office Vertical Derrick.

\section{Results}

\subsection{Results of Relative Humidity Monitoring}

The results of relative humidity and temperature monitored during June $1^{\text {st }}$ to July $25^{\text {th }}, 2018$, along with precipitation observed by Japan Meteorological Agency are shown in Figure 2. These results indicate that places with thinner cover thickness tend to be influenced by weather events such as rain.

\subsection{Results of Concrete Spalling and Cover Thickness}

Concrete spalling had been observed every 3 months since February 2011. The Figures used below are based on the observation record. Figure 3 shows the accumulated number of concrete flakes, which increased by the rate of approximately 200 pieces per year. However, the influence of weather events or earthquake was still unclear. Figure 5 shows the size and numbers of the flakes, which are around $5 \sim 10 \mathrm{~cm}$ in diameter. In addition, cover thickness 
Kaiting Su, Kei-ichi Imamoto, Takafumi Noguchi, Manabu Kanematsu, Hitoshi Hamasaki, Kohji Teranishi, Chizuru Kiyohara and Munenori Yamada

and level of rebar corrosion in relation to concrete spalling were also investigated. The subjects investigated included pillars and beams of 4 directions from $1^{\text {st }}$ floor to $3^{\text {rd }}$ floor. The aggregated results of cover thickness by are shown in Figure 6. According to the results, rebar exposure induced by concrete spalling occurred when cover thickness was less than $25 \mathrm{~mm}$.
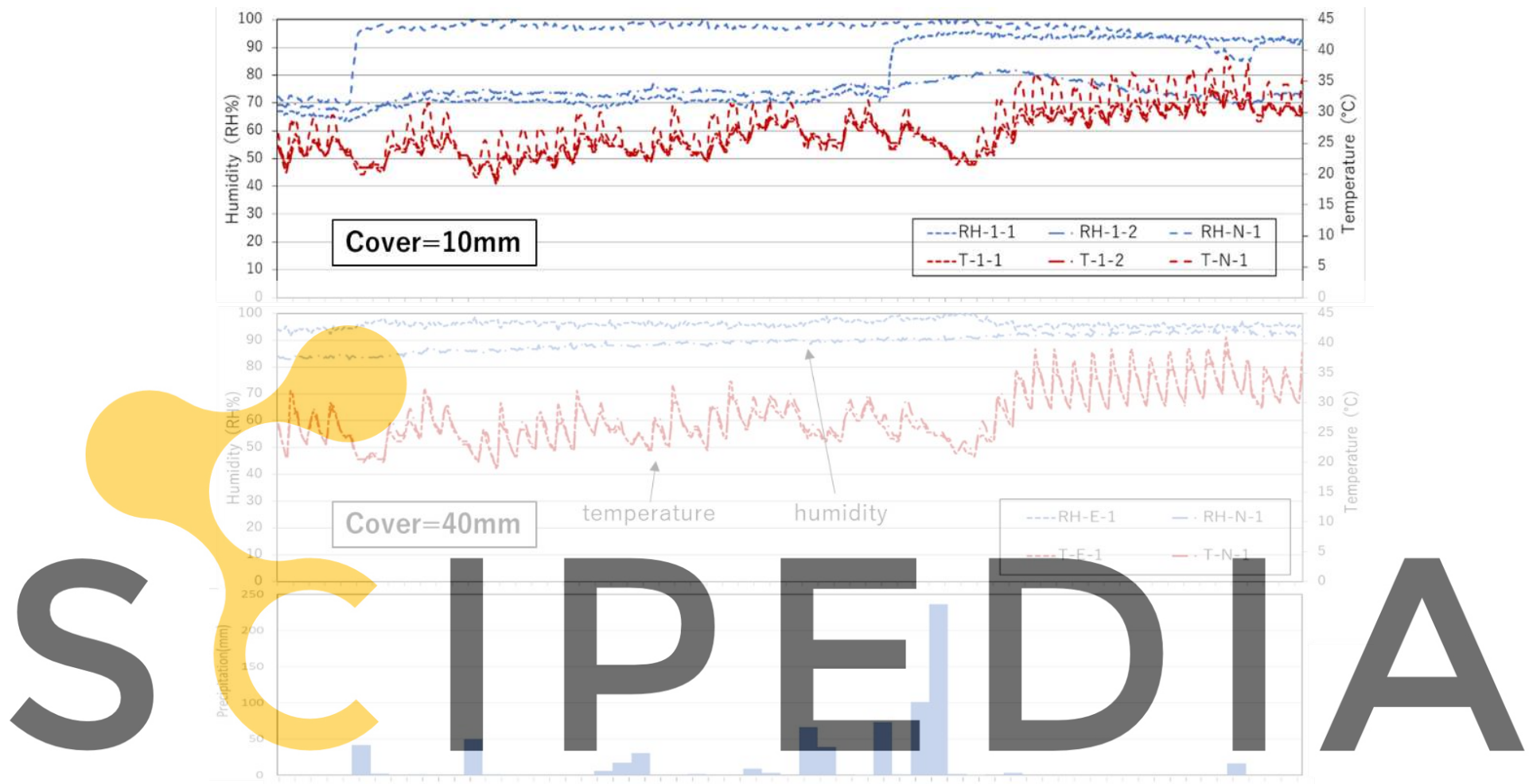

Register for free at httpS/4WWW:Scipedia.com to download the version without the watermark

Figure 2. Evolution of Relative Humidity and Temperature (Upper: Cover=10mm, Middle: Cover=40 mm) and Precipitation.

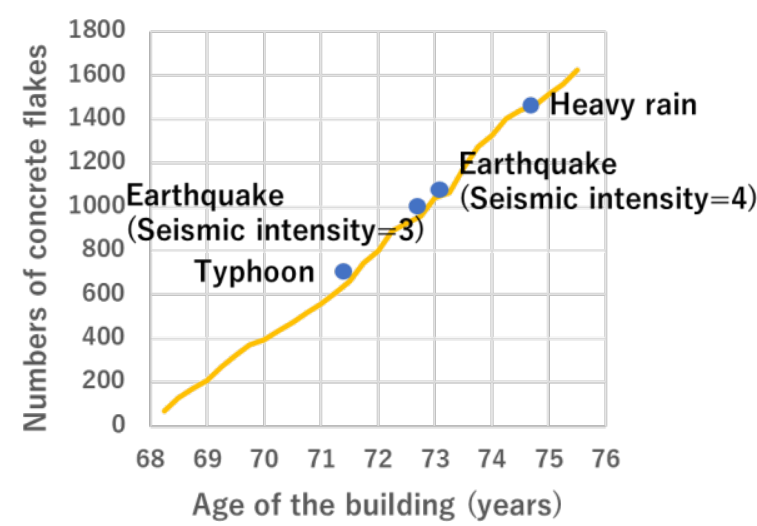

Figure 3. Accumulated number of concrete flakes.

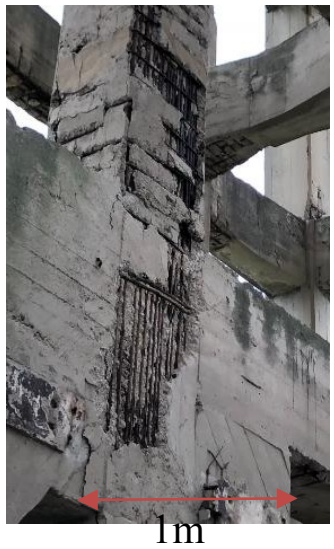

Figure 4. Rebar exposure due to spalling. 


\subsection{Results of Air Permeability Test and Carbonation}

The results of the relation between the coefficient of carbonation and the coefficient of air permeability are shown in figure 7, along with previous investigation results of other buildings. The coefficient of carbonation is calculated by $\mathrm{C} / \sqrt{\mathrm{t}}$, where $\mathrm{C}$ stands for the depth of carbonation and $t$ stands for years of use. The depth of carbonation is measured by applying phenolphthalein solution to concrete cores following the instructions in JIS A 1152. The coefficient of air permeability is calculated by the Torrent method (double chamber method). According to previous investigations, the coefficient of air permeability increases when the coefficient of carbonation increases. According to Figure 5, the results Vertical Derrick are within the range of previous results.
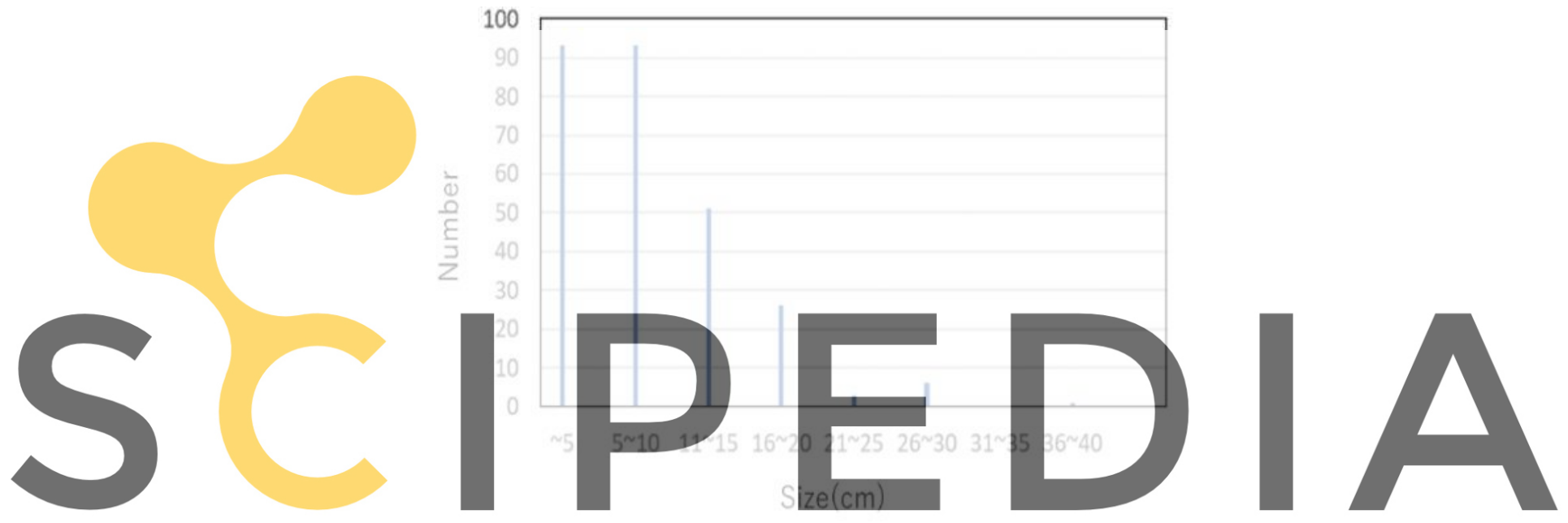

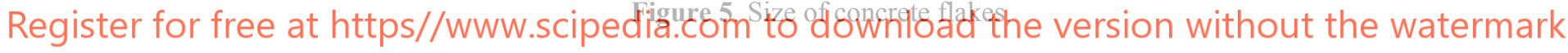

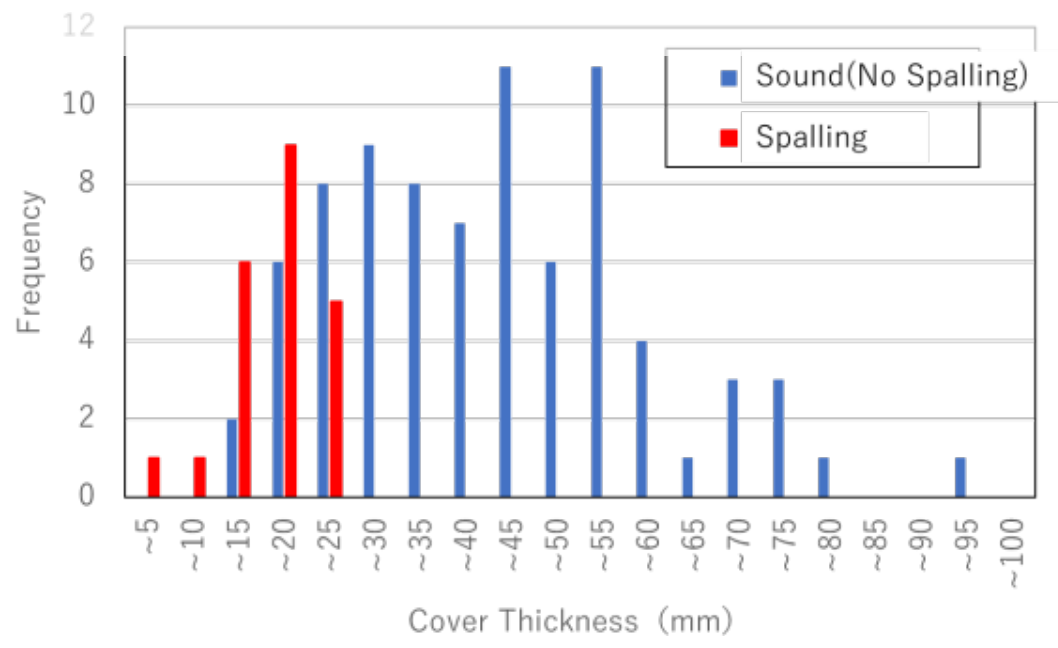

Figure 6. Cover thickness and rebar expose. (Tomotaka Ide, 2019) 


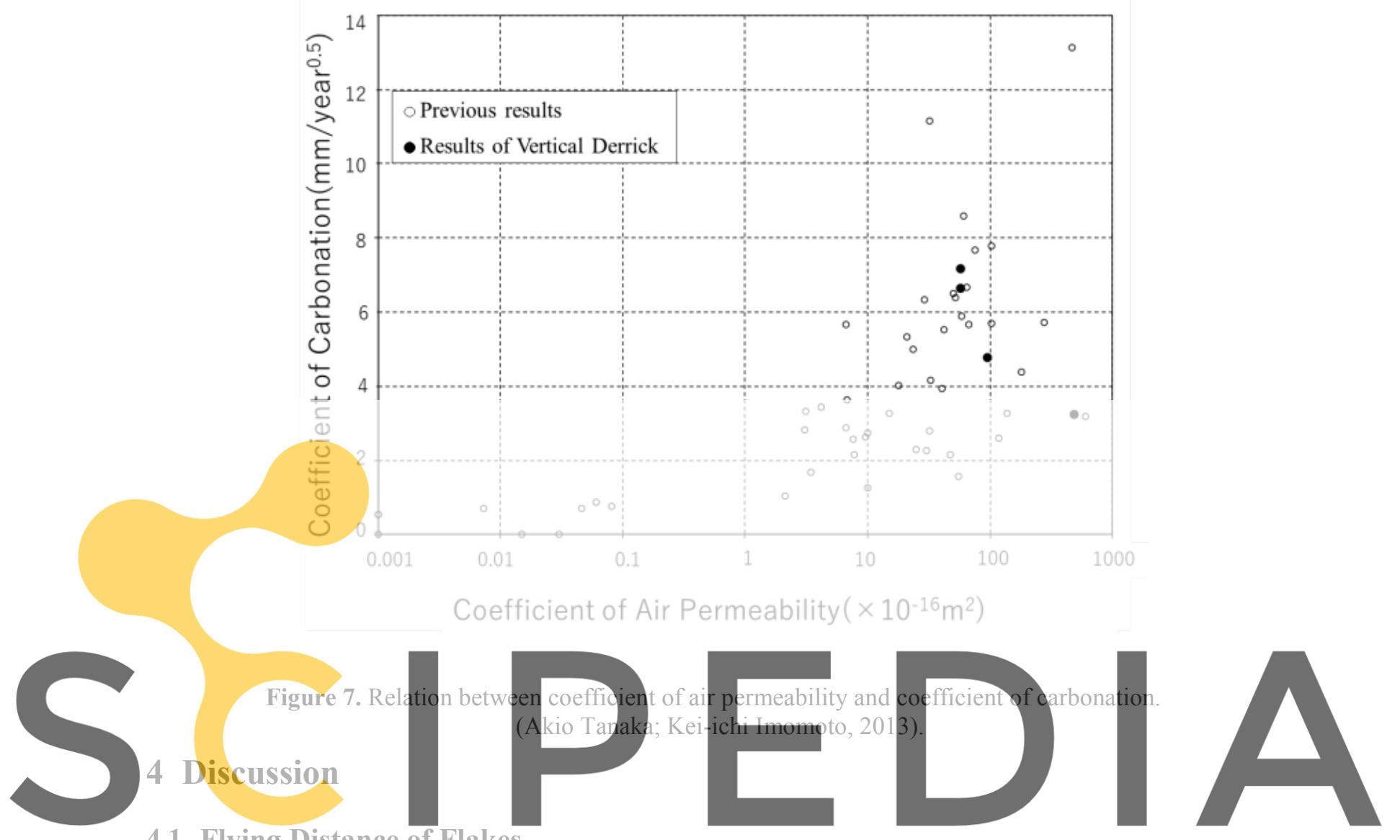

\subsection{Flying Distance of Flakes}

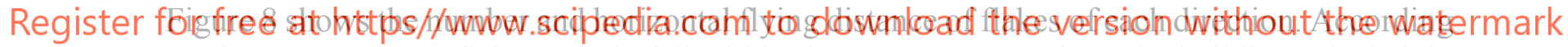
to Figure 8, concrete flakes mostly fell within the 7 meters range from the building. The height of the building was 47 meters. For the flying distance of 7 meters, the falling degree was $21.7^{\circ}$ and the horizontal flying distance was 0.15 times the height of the building. Concrete flakes that fell out of this range needs further discussion concerning the windswept condition of this location. Table 2 shows the percentage of the spalling area of each direction. According to Table 2, the percentages of spalling area are between $5 \sim 10 \%$.

Table 2. Spalling percentage of each direction. (spalling/total area of each side of the wall).

\begin{tabular}{|c|c|c|c|}
\hline West & South & North & East \\
\hline $9.91 \%$ & $5.20 \%$ & $9.35 \%$ & $3.71 \%$ \\
\hline
\end{tabular}



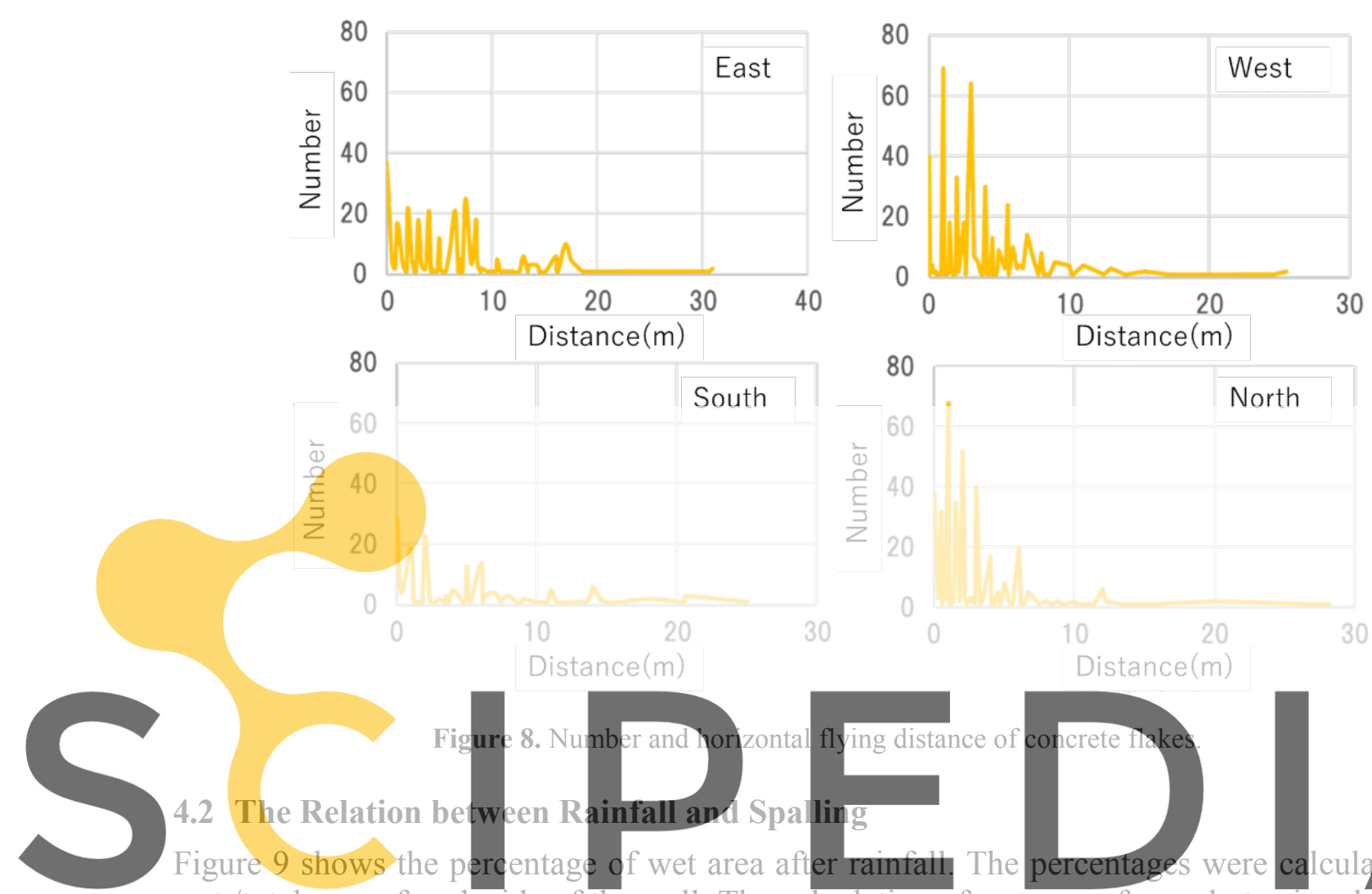

4.2 The Relation between Rainfall and Spalling

Figure 9 shows the percentage of wet area after rainfail
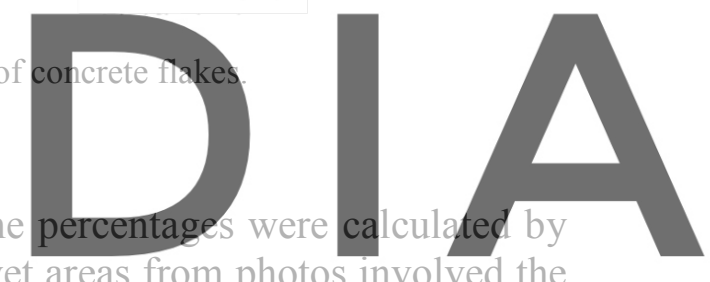

wet /total area of each side of the wall. The calculation of wet areas from photos involved the

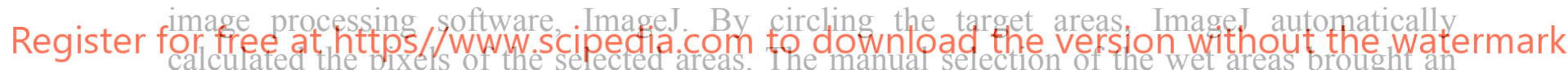
uncertainty to the results. To increase accuracy, image processing method should be further discussed in future researches. According to the results, the north and the west side with higher number of concrete flakes also showed higher percentage of the wet area. At this location, due to northwest wind blew throughout the year, the north and the west side of the building were more possible to be affected by rainfall than the south and the east side. This observation indicates that there might be a relation between spalling and rainfall. The following equations are proposed considering the relation between the two.

$$
\begin{gathered}
\text { Coefficient of Rainfall }=\text { Percentage of Wet Area } \times \text { Number of Days with Precipitation over 10mm } \\
\text { Percentage of Spalling Area }=\text { Years after Carbonation reaches } 25 \mathrm{~mm} \times \text { Coefficient of Rainfall } \times \\
\text { Percentage of Cover Thickness Less than } 25 \mathrm{~mm} \times \alpha
\end{gathered}
$$

Table 3 shows the results of the Coefficient of Rainfall and the empirical coefficient $\alpha$ by applying equation (1) and (2) to the north and the south side. When the value of $\alpha$ is 0.006 , according to the Coefficient of Rainfall in Table 3, the estimated values of spalling area along with measured spalling area are shown in Table 4. 
Kaiting Su, Kei-ichi Imamoto, Takafumi Noguchi, Manabu Kanematsu, Hitoshi Hamasaki, Kohji Teranishi, Chizuru Kiyohara and Munenori Yamada

Table 3. Results of the coefficient of rainfall and the empirical coefficient $\alpha$ of the south and the north side.

\begin{tabular}{|c|c|c|}
\hline & South & North \\
\hline Coefficient of Rainfall & 1.231 & 4.537 \\
\hline$\alpha$ & 0.0062 & 0.0012 \\
\hline
\end{tabular}

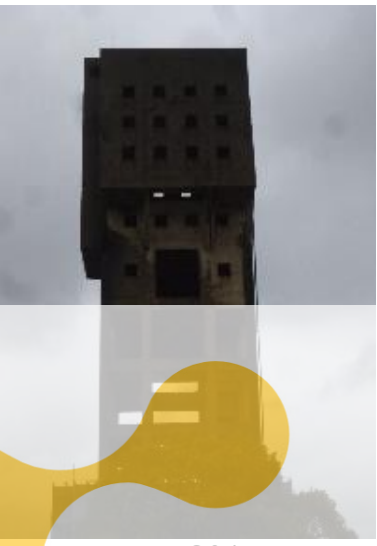

West, $78 \%$ wet

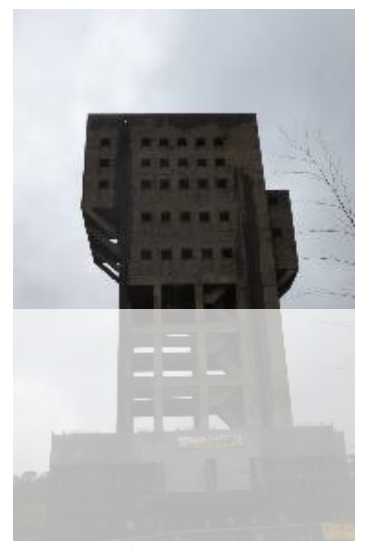

South, $19 \%$ wet

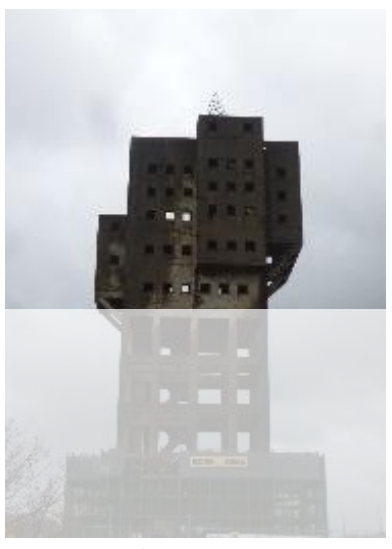

North, $70 \%$ wet

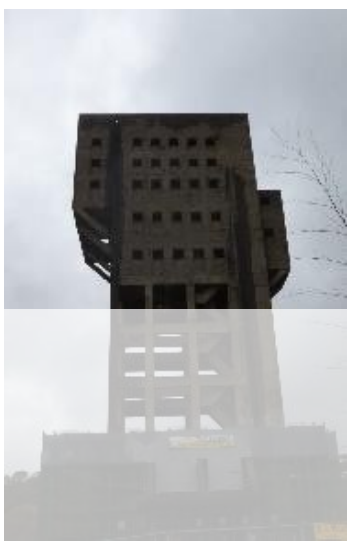

East, 36\% wet

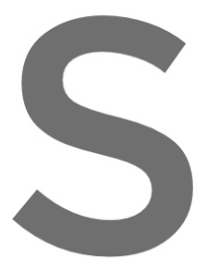

Figure 9. Percentage of wet area (wet/total area of each side) after rainfall.
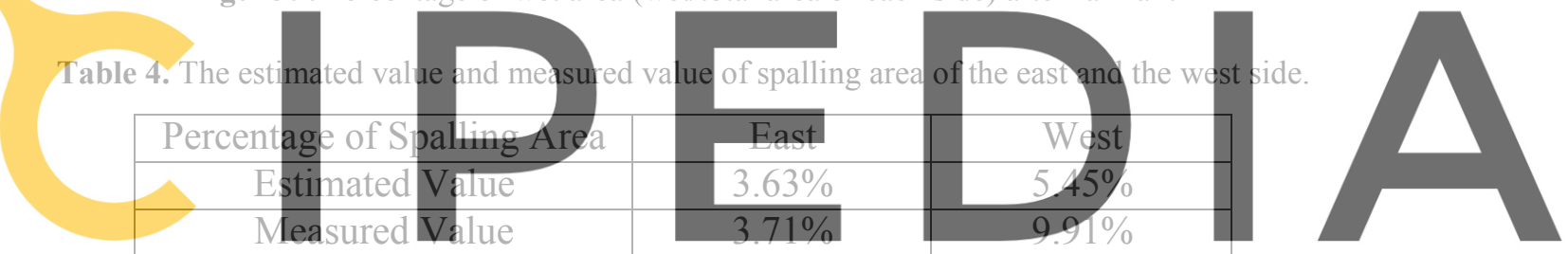

Register for free at https//www.scipedia.com to download the version without the watermark 5 Conclusions

Post peak behaviors of carbonated concrete structures are as follows.

- Concrete spalling flakes increased by the rate of 200 pieces per year while the influence of climate events was still unclear. The sizes of the flakes were around $10 \mathrm{~cm}$ in diameter.

- The horizontal flying distance of concrete flakes were approximately 0.15 times the height of the building.

- The sides of the walls with higher proportion of concrete spalling also present higher proportion of wet area during rainfall. 
Kaiting Su, Kei-ichi Imamoto, Takafumi Noguchi, Manabu Kanematsu, Hitoshi Hamasaki, Kohji Teranishi, Chizuru Kiyohara and Munenori Yamada

\section{Acknowledgements}

Thanks to the board of education of Shime-Cho, who had given the chance for the investigation of Shime Mining Office Vertical Derrick and cooperated with the aggregation of concrete flakes and other deterioration investigations.

\section{ORCID}

Kaiting Su: https://orcid.org/0000-0003-2503-4154

Kei-ichi Imamoto: https://orcid.org/0000-0001-8174-8827

Takafumi Noguchi: https://orcid.org/0000-0001-6115-2292

Manabu Kanematsu: https://orcid.org/0000-0003-2473-0625

Hitoshi Hamasaki: https://orcid.org/0000-0002-1830-3734

Chizuru Kiyohara: https://orcid.org/0000-0003-1286-9056

\section{References}

Akio Tanaka and Kei-ichi Imomoto. (2013). Evaluation of Carbonation Progress of Existing Concrete Structure Based on Air Permeability of Cover Concrete J. Struct. Constr. Eng., AIJ, 78(691), 1539-1544.

Japan Meteorological Agency. Earthquake information centered on the west off the Satsuma Peninsula.

Kyushu Reginal Development Association. Disaster History Information in Kyushu.

Kyushu Sangyo University. The possibility of Reservation of the Former Shime Mining Office Vertical Derrick.

Shime Town. Important Cultural Property Plan for Reservation and Utilization of the Former Shime Mining Office Vertical Derrick.

Tomotaka Ide. (2019). Investigation of Shime Old Coal Mine Tower-Part 1 Result of the Cover Depth and Rebar

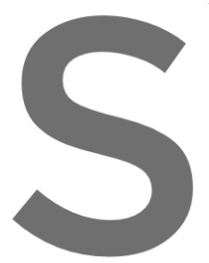
Corrosion, and Humidity
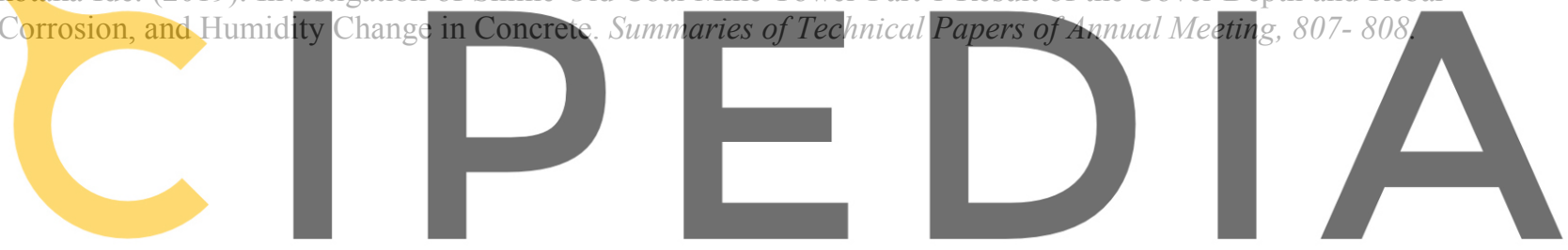

Register for free at https//www.scipedia.com to download the version without the watermark 